\title{
Relative Bioavailability of Ciprofloxacin Doses (750 and 1000) mg in Healthy Male Volunteers by Using HPLC Method
}

Mallah $E^{* 1}$, Arafat B ${ }^{2}$, Al khawaja B ${ }^{1}$, Abu Dayyih $\mathrm{W}^{1}$, Abu Awad A ${ }^{1}$, Hroub HA ${ }^{1}$, Hamad $\mathrm{M}^{3}$ and Arafat $\mathrm{T}^{1}$

${ }^{1}$ Faculty of Pharmacy and Medical Sciences, University of Petra, Amman, Jordan

${ }^{2}$ Faculty of Pharmacy Medical Sciences, Al-Ahliyya Amman University, Amman, Jordan

${ }^{3}$ Collage of Science and Health Professions, King Saud Bin Abdulaziz University for Health Sciences (KSAU-HS),

Jeddah, KSA

*Corresponding author: Mallah E, Faculty of Pharmacy and Medical Sciences, University of Petra, Amman, Jordan, Fax: 00962(6)5715570, Tel: 00962(6)5715546, E-mail: emallah@uop.edu.jo

Citation: Mallah E, Arafat B, khawaja B, Abu Dayyih W, Abu Awad A, et al. (2015) Relative Bioavailability of CiprofloxacinDoses (750 and 1000) mg in Healthy Male Volunteers by Using HPLC Method. J Bioequiv 1(1): 101. doi: 10.15744/2575-551X.1.101

Received Date: February 07, 2015 Accepted Date: September 01, 2015 Published Date: September 03, 2015

\begin{abstract}
A new, stable and accurate high performance liquid chromatography ultraviolet spectrophotometric method for quantitation of Ciprofloxacin in human plasma was developed and validated. The chromatographic separation was performed on a reversed phase BDS (base deactivated silica) C18 analytical column; $150 \times 4.6 ; 5 \mu \mathrm{m}$ particle size. The mobile phase consisted of a mixture of $1 \mathrm{ml}$ triethylamine (TEA)/1L, water and acetonitrile $(80: 20 \mathrm{v} / \mathrm{v})$. The $\mathrm{pH}$ of mobile phase was adjusted to 2.5 by using phosphoric acid and the detector was set at a wavelength of $280 \mathrm{~nm}$. Accuracy, precision, linearity and stability of the analytical method were done. The regression equations are linear $\left(\mathrm{R}^{2}\right.$ was 0.999$)$ over the calibration curve concentration range of $(0.10-8.0) \mu \mathrm{g} / \mathrm{ml}$. Inter and Intra precision $(\% \mathrm{CV})$ were less than $6.102 \%$ and $6.82 \%$ respectively.

Two different tablet doses of Ciprofloxacin (750 and 1000) mg were administrated to 28 healthy male volunteers in cross over design, blood samples were taken from the participant at different time intervals and then Ciprofloxacin concentrations were analyzed. The bioavailability and pharmacokinetic parameters were calculated, the maximum absorption time ( $\mathrm{t} \max$ ) was equal for both doses (3.0hr). The maximum concentrations (Cmax) were (1.93 and 2.45) $\mu \mathrm{g} / \mathrm{ml}$ for the (750 and 1000) mg doses, respectively. Regarding area under the curve (AUC) for 750 and $1000 \mathrm{mg}$ doses were found (15.30 and $\left.19.12 \mu \mathrm{g}^{\star} \mathrm{t} / \mathrm{ml}\right)$, respectively. Obviously, the variation was significantly found in Ciprofloxacin doses ( $\mathrm{p}$ value less than 0.05 ) and the pharmacokinetic data confirm the relative trend of bioavailability and absorption of Ciprofloxacin in human plasma.
\end{abstract}

Keywords: Ciprofloxacin; Bioavailability; HPLC; Pharmacokinetic; Validation

\section{Introduction}

Ciprofloxacin which regard as antibacterial agent [1-cyclopropyl-6-fluoro-1,4-dihydro-4-oxo-7-(1-piperazinyl)-3 quinolinecarboxylic acid] is a fluoroquinolone derivative (Figure 1) related structurally to nalidixic acid. It hasbroad-spectrum antibacterial agent which active against gram-positive and gram-negative bacteria [1-4].

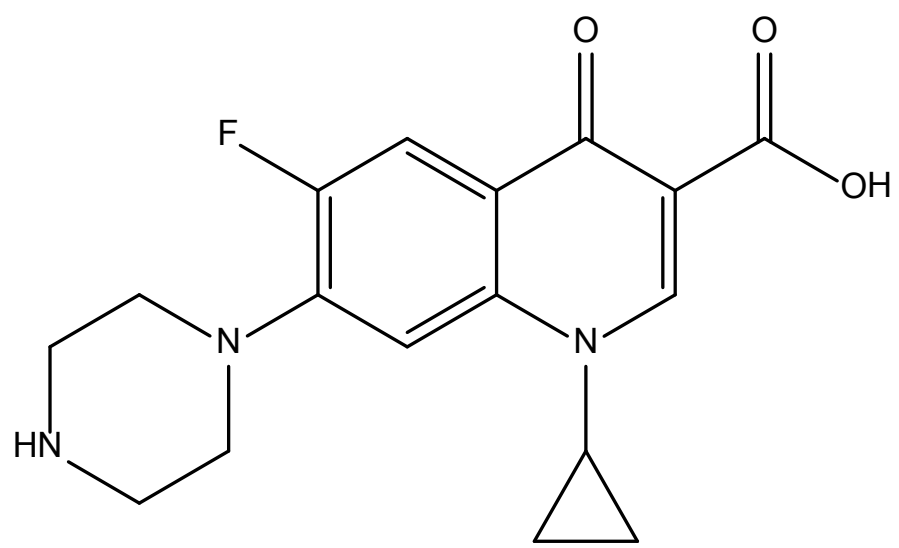

Figure 1: Ciprofloxacin chemical structure 
The main mechanism of action of ciprofloxacin is bacterial DNA gyrase which is a member of the class of type II topoisomerasesinhibition, which results in disruption of DNA replication. Ciprofloxacin is effective after both oral and intravenous administration. It has proven as an effective drug for treatment of a wide variety of infections, including acute and chronic urinary tract infections, sexually transmitted diseases, skin and bone infections, gastrointestinal infections and lower respiratory tract infections [1-6]. Compared with nalidixicacid and other early quinolones, fluoroquinolones acquired a higher clinical relevance due to their broad antimicrobial spectrum of activity, enhanced pharmacokinetic properties and tolerable and relatively safe profile [7]. Absorption after oral administration is rapid; peak serum ciprofloxacin concentrations (Cmax) between 0.8 and $3.9 \mu \mathrm{g} / \mathrm{ml}$ are reached after 1 to 2 hours following oral administration of single dose of $250-750 \mathrm{mg}$. The drug has a large apparent volume of distribution between 2.1-5 L/kg which indicated the penetration of the drug into most tissue. It is concentrated in various body fluids and tissues, such as bile, prostate, gallbladder, kidney, lung, and livertissue. Ciprofloxacin is mainly excreted un-metabolized in the urine and feces. However, small amounts of metabolites have been detected. Intestinal excretion shows to be the predominant route of gastrointestinal elimination, but bile excretion takes place too. The elimination half-life is about 3 to 5 hours [6,8-11]. This study was set with the aim of determination of the bioavailability of two different tablet doses of ciprofloxacin (750 and 1000) mg after oral administration in healthy human volunteers.

\section{Experimental part}

\section{Bioequivalence study protocol}

Healthy adult 28 male volunteers were enrolled in the study after providing written informed consent. Volunteers were selected upon inclusion/exclusion criteria.

Subjects were enrolled in this study after obtaining their medical history, biochemical, serological, hematological and urine analysis. Participants were found healthy since there was no significant abnormality in their results. Exclusion criteria included any medical history of a significant gastrointestinal problem which could prevent the absorption of the drug and any previous history of allergy to fluoroquinolone derivatives. In addition, any subject needs chronic medication, such as theophylline, antacids, iron, or vitamins was excluded.

Prior to the study, the volunteers were informed on the nature, purpose, duration and risk of the study. They were also informed that they could withdraw from the study at any time. The study protocol was approved by the local institutional review board. The average age of the volunteers is $35( \pm 5)$ years with a mean body mass index of $19( \pm 2)$. Volunteers were randomly divided into 2 groups consisting of 14 volunteers in each group in cross over design. Group 1 received $750 \mathrm{mg}$ of ciprofloxacin while the second group receive $1000 \mathrm{mg}$. After overnight fasting, each volunteer received the treatment with $250 \mathrm{~mL}$ of water in the morning.

\section{Blood Sampling}

Venous blood samples were collected before and after drug administration at $(0.50,0.75,1.00,1.25,1.50,1.75,2.00,2.50,3.00,3.50$, $4.00,4.50,5.00,6.00,8.00,10.00,12.00,14.00$ and 24.00) hours. An intravenous cannula was placed into the volunteers' forearm vein before drug administration. The blood samples were withdrawn in labeled tubes containing lithium heparin, and readily centrifuged at room temperature at $5000 \mathrm{rpm}$ for 10 minutes at room temperature. The separated plasma was taken and stored at $40{ }^{\circ} \mathrm{C}$ till analysis.

\section{HPLC analysis and chromatographic conditions}

Plasma concentrations of ciprofloxacin were analyzed using a sensitive and selective high-performance liquid chromatographic (HPLC) method. The HPLC (FINNIGAN SURVEYOR) system consisted of a pump (Solvent delivery systems pump (LC Pump Plus)) with sample injector port (Autosampler Plus) and a programmable UV/Vis detector (UV-VIS plus Detector). The detector was set at a wavelength of $280 \mathrm{~nm}$.

The chromatographic separation was performed on a reversed phase BDS C18 analytical column; $150 \times 4.6 ; 5 \mu \mathrm{m}$ particle size (Hypersil Thermo Electron Corporation). The mobile phase consisted of a mixture of $1 \mathrm{ml}$ TEA (Fisher scientific Inc )/1L of water and acetonitrile (Fisher scientific Inc) $(80: 20 \mathrm{v} / \mathrm{v})$. The $\mathrm{pH}$ of mobile phase was adjusted to 2.5 by using phosphoric acid (Fisher scientific Inc). Umbelliferone (Toronto Research Chemicals Inc.) was used as an internal standard. The flow rate was $1.0 \mathrm{ml} / \mathrm{min}$.

In order to perform the sample extraction, the following experimental procedure was followed: $100 \mu$ aliquot of each test sample (blank, zero, standards, quality control samples or volunteer samples) was added to $200 \mu \mathrm{lof}$ Internal Standard (10 $\mu \mathrm{g} / \mathrm{ml}$ umbelliferon in acetonitrile as precipitating agent). Then after vortex for 1.0 minute and centrifuge at $15000 \mathrm{rpm}$ for $10 \mathrm{minutes}$, the supernatant was transfer to a flat bottom insertand $10 \mu \mathrm{l}$ was injected directly into HPLC system.

\section{Method validation}

In order to demonstrate the reliability of our method, accuracy, precision, linearity and stability tests were carried out according to EMEA 2012 guideline on bioanalytical method validation. Regarding linearity test 7 calibration points $(0.1,0.5,1.0,2.0,3.0,5.0$ and 8.0) $\mu \mathrm{g} / \mathrm{ml}$ were involved, a series of 6 injections to each calibration concentration level. Peak areas of the calibration standards were plotted in the Y-axis against the nominal standard concentration, and the linearity of the plotted curve was evaluated via calculation of the correlation coefficient $\left(\mathrm{R}^{2}\right)$ which should be more than 0.98 . 
The intra-day precision and accuracy were evaluated by analyzing 6 replicates of the quality control (QC) samples (low, mid, high) and lower limit of quantification (LLOQ) samples on a single day. The inter-day precision and accuracy were determined by analyzing three runs of QC samples and LLOQ samples on three different days. The accuracy (\%) was calculated by dividing a measured mean concentration over the nominal concentration. Precision was presented as CV\%. The acceptable values of accuracy and precision are below 15\% except for LLOQ, accuracy and precision should be below $20 \%$.

Stability of the analyte in the plasma is evaluated using low and high QC samples which are analyzed immediately after preparation and after the applied storage condition that are to be evaluated. The QC samples are analyzed against a calibration curve, obtained from freshly spiked calibration standards, and the obtained concentration are compared to the nominal concentrations. The following stability tests were carried out:

- Autosampler stability

- Short term stability of the analyte in plasma at room temperature for 24 hours.

- Freeze and thaw stability of the analyte in the matrix from freezer storage conditions to room temperature or sample processing temperature for three cycles.

\section{Results and Discussion}

By continuing our investigations of drug analysis in biological fluids by using chromatographic techniques [12,13], the current chromatographic method of ciprofloxacin and IS were separated within 7.5 min run time (Figure 2). The retention time of ciprofloxacin was 5.1 minutes, while the IS was eluted at 7.1 minutes.
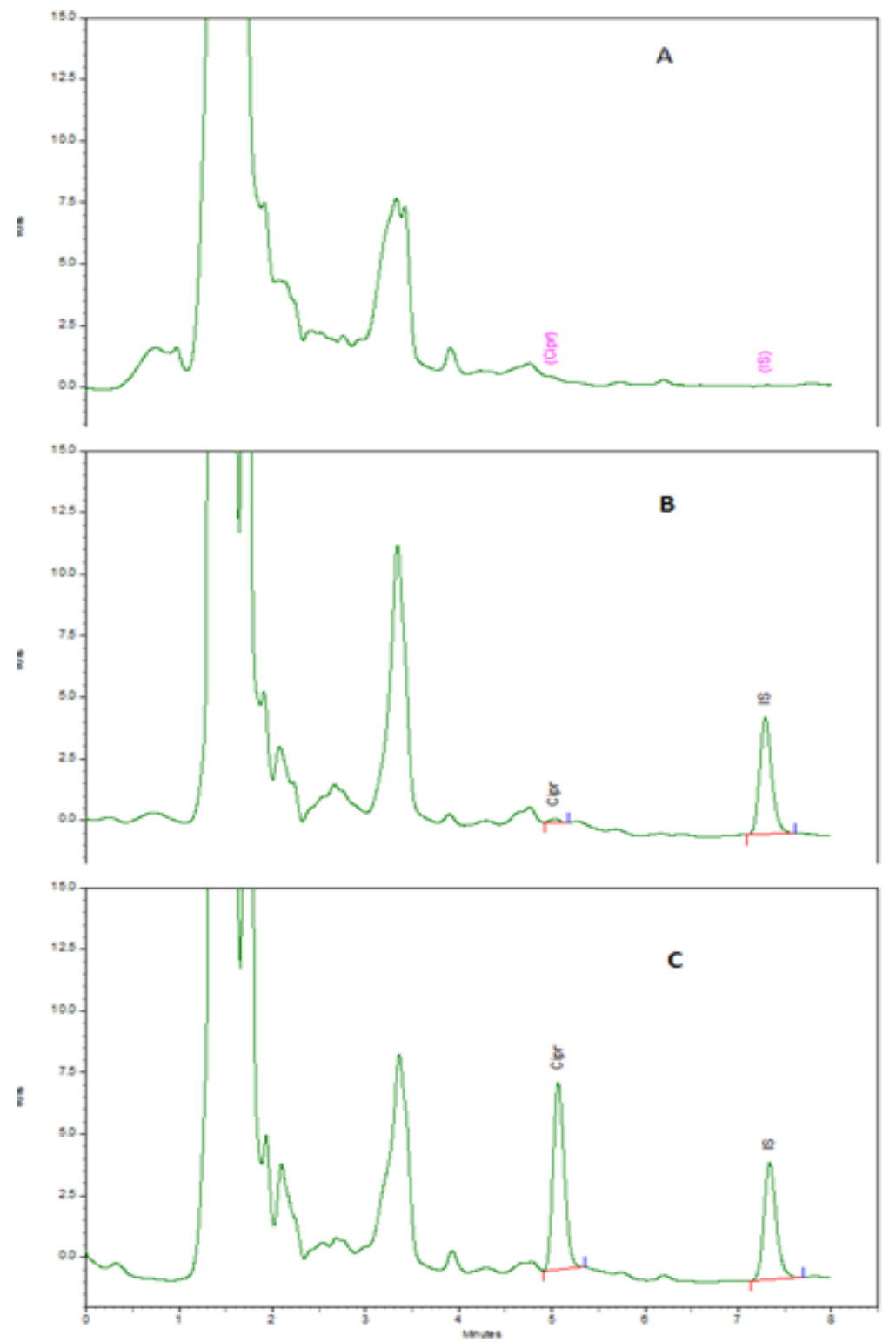

Figure 2: (A) Chromatograms of blank sample (B) LLOQ: Ciprofloxacin $(0.1 \mu \mathrm{g} / \mathrm{ml})$ and IS $(10 \mu \mathrm{g} / \mathrm{ml})$, eluted at 5.1 and $7.3 \mathrm{~min}$, respectively. (C) QC high: Ciprofloxacin $(6.5 \mu \mathrm{g} / \mathrm{ml})$ and IS $(10 \mu \mathrm{g} / \mathrm{ml})$. 


\section{Validation results}

Accuracy and precision: Over the range of concentrations of each analyte, the intra-day accuracy \% was (97.38-103.71\%). Meantime, the inter-day accuracies were (98.07-102.22\%) (Table 1).

Inter and intra precision and accuracy were evaluated with different concentration of ciprofloxacin. Inter and Intraprecision (\% CV) were less than $6.102 \%$ and $6.82 \%$ respectively (Table 1 ).

These results indicate that this method is precise and accurate over the studied concentration range.

\begin{tabular}{|c|c|c|c|c|c|c|c|c|c|c|c|c|}
\hline & \multicolumn{3}{|c|}{ LLOQ $0.1 \mu \mathrm{g} / \mathrm{ml}$} & \multicolumn{3}{|c|}{ QCL $0.3 \mu \mathrm{g} / \mathrm{ml}$} & \multicolumn{3}{|c|}{$\mathrm{QCM} 4.0 \mu \mathrm{g} / \mathrm{ml}$} & \multicolumn{3}{|c|}{ QCH $6.5 \mu \mathrm{g} / \mathrm{ml}$} \\
\hline & $\begin{array}{l}\text { Day } \\
\text { One }\end{array}$ & $\begin{array}{l}\text { Day } \\
\text { Two }\end{array}$ & $\begin{array}{l}\text { Day } \\
\text { Three }\end{array}$ & $\begin{array}{l}\text { Day } \\
\text { One }\end{array}$ & $\begin{array}{l}\text { Day } \\
\text { Two }\end{array}$ & $\begin{array}{l}\text { Day } \\
\text { Three }\end{array}$ & $\begin{array}{l}\text { Day } \\
\text { One }\end{array}$ & $\begin{array}{l}\text { Day } \\
\text { Two }\end{array}$ & $\begin{array}{l}\text { Day } \\
\text { Three }\end{array}$ & $\begin{array}{l}\text { Day } \\
\text { One }\end{array}$ & $\begin{array}{l}\text { Day } \\
\text { Two }\end{array}$ & $\begin{array}{l}\text { Day } \\
\text { Three }\end{array}$ \\
\hline & 0.089 & 0.102 & 0.101 & 0.292 & 0.307 & 0.319 & 4.037 & 4.001 & 4.086 & 6.543 & 6.659 & 6.562 \\
\hline & 0.099 & 0.093 & 0.094 & 0.296 & 0.286 & 0.302 & 4.033 & 3.951 & 4.249 & 6.542 & 6.642 & 6.612 \\
\hline & 0.091 & 0.096 & 0.097 & 0.300 & 0.321 & 0.285 & 3.910 & 4.278 & 4.227 & 6.441 & 6.688 & 6.630 \\
\hline & 0.103 & 0.091 & 0.105 & 0.303 & 0.290 & 0.285 & 3.906 & 4.292 & 4.161 & 6.468 & 6.706 & 6.445 \\
\hline & 0.106 & 0.105 & 0.098 & 0.284 & 0.294 & 0.337 & 3.953 & 4.181 & 4.133 & 6.705 & 6.820 & 6.471 \\
\hline & 0.096 & 0.097 & 0.102 & 0.282 & 0.279 & 0.340 & 3.936 & 4.188 & 4.076 & 6.681 & 6.817 & 6.559 \\
\hline Mean & \multicolumn{3}{|l|}{0.098} & \multicolumn{3}{|l|}{0.300} & \multicolumn{3}{|l|}{4.089} & \multicolumn{3}{|l|}{6.611} \\
\hline STD & \multicolumn{3}{|l|}{0.005} & \multicolumn{3}{|l|}{0.018} & \multicolumn{3}{|l|}{0.130} & \multicolumn{3}{|l|}{0.116} \\
\hline CV\% & \multicolumn{3}{|l|}{5.291} & \multicolumn{3}{|l|}{6.102} & \multicolumn{3}{|l|}{3.177} & \multicolumn{3}{|l|}{1.756} \\
\hline Accuracy \% & \multicolumn{3}{|l|}{98.07} & \multicolumn{3}{|l|}{100.04} & \multicolumn{3}{|l|}{102.22} & \multicolumn{3}{|l|}{101.70} \\
\hline
\end{tabular}

Table1: Inter-day accuracy and precision of Ciprofloxacin

Stability: Regarding stability; autosampler, short term stability at room temperature and freeze and thaw stability; all results were within the accepted range since the accuracy \% doesn't exceed 15\% for both QC low and QC high (Tables 2-4).

\begin{tabular}{|c|c|c|c|c|}
\hline & \multicolumn{2}{|c|}{ QCL } & \multicolumn{2}{c|}{ QCH } \\
\hline \multirow{2}{*}{ Time } & Measured Conc. & Accuracy \% & Measured Conc. & Accuracy \% \\
\hline \multirow{3}{*}{ 0.00 Hour } & 0.321 & 106.89 & 6.504 & 100.07 \\
\cline { 2 - 5 } & 0.318 & 105.84 & 6.548 & 100.74 \\
\cline { 2 - 5 } & 0.323 & 107.78 & 6.502 & 100.03 \\
\hline \multirow{3}{*}{ 24.00 Hours } & 0.306 & 102.03 & 6.509 & 100.14 \\
\cline { 2 - 5 } & 0.322 & 107.49 & 6.564 & 100.98 \\
\cline { 2 - 5 } & 0.329 & 109.53 & 6.574 & 101.13 \\
\hline
\end{tabular}

Table 2: Autosampler stability of QC low, med and high samples of ciprofloxacin

\begin{tabular}{|c|c|c|c|c|}
\hline & \multicolumn{2}{|c|}{ QCL } & \multicolumn{2}{c|}{ QCH } \\
\hline \multirow{2}{*}{ Time } & Measured Conc. & Accuracy \% & Measured Conc. & Accuracy \% \\
\hline \multirow{3}{*}{ 0.00 Hour } & 0.321 & 106.89 & 6.504 & 100.07 \\
\cline { 2 - 5 } & 0.318 & 105.84 & 6.548 & 100.74 \\
\cline { 2 - 5 } & 0.323 & 107.78 & 6.502 & 100.03 \\
\hline \multirow{3}{*}{ 24.00 Hours } & 0.303 & 100.84 & 6.405 & 98.54 \\
\cline { 2 - 5 } & 0.320 & 106.59 & 6.512 & 100.19 \\
\cline { 2 - 5 } & 0.317 & 105.58 & 6.443 & 99.12 \\
\hline
\end{tabular}

Table3: Short term stability of QCs samples of ciprofloxacin

\begin{tabular}{|c|c|c|c|c|}
\hline \multirow{2}{*}{ Time } & \multicolumn{2}{|c|}{ QCL } & \multicolumn{2}{c|}{ QCH } \\
\hline \multirow{3}{*}{ 0.00 Hour } & Measured Conc. & Accuracy \% & Measured Conc. & Accuracy \% \\
\cline { 2 - 5 } & 0.321 & 106.89 & 6.504 & 100.07 \\
\cline { 2 - 5 } & 0.318 & 105.84 & 6.548 & 100.74 \\
\hline \multirow{3}{*}{ 24.00 Hours } & 0.323 & 107.78 & 6.502 & 100.03 \\
\cline { 2 - 5 } & 0.303 & 100.99 & 6.305 & 97.00 \\
\cline { 2 - 5 } & 0.308 & 102.76 & 6.412 & 98.65 \\
\hline
\end{tabular}

Table 4: Freeze-thaw stability of QCs samples of ciprofloxacin 
Linearity: Calibration curves were linear over the concentrations range from 0.1 to $8 \mu \mathrm{g} / \mathrm{ml}$ for ciprofloxacin $\left(\mathrm{R}^{2}=0.99\right)($ Figure 3$)$.

\begin{tabular}{|c|c|c|c|}
\hline correlation & Slope & $\mathrm{R}^{2}$ & Intercept \\
\hline $\mathbf{0 . 9 9 9 9 6 3}$ & $\mathbf{0 . 2 1 8 6 4 0}$ & $\mathbf{0 . 9 9 9 9 2 6}$ & $\mathbf{0 . 0 0 3 4 1 0}$ \\
\hline
\end{tabular}

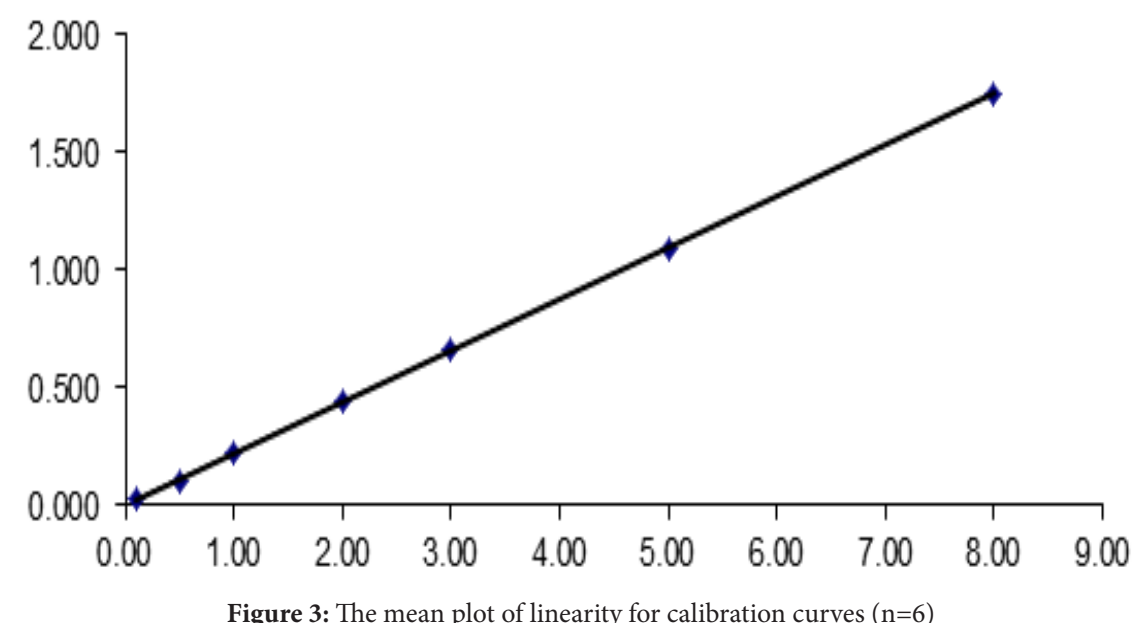

\section{Bioavailability of the different doses of ciprofloxacin}

This study was set with the aim of comparing the pharmacokinetic parameters of two doses of ciprofloxacin in human volunteers [14]. Previous bioequivalence studies were used to evaluate different formulation of the same dose [15,16]. Plasma profiles at both doses were blotted as seen in figure 4, pharmacokinetic parameters (Cmax,Tmax, $\mathrm{AUC}_{0-24}, \mathrm{t}$-half and Kel) were calculated as shown in table 5 .

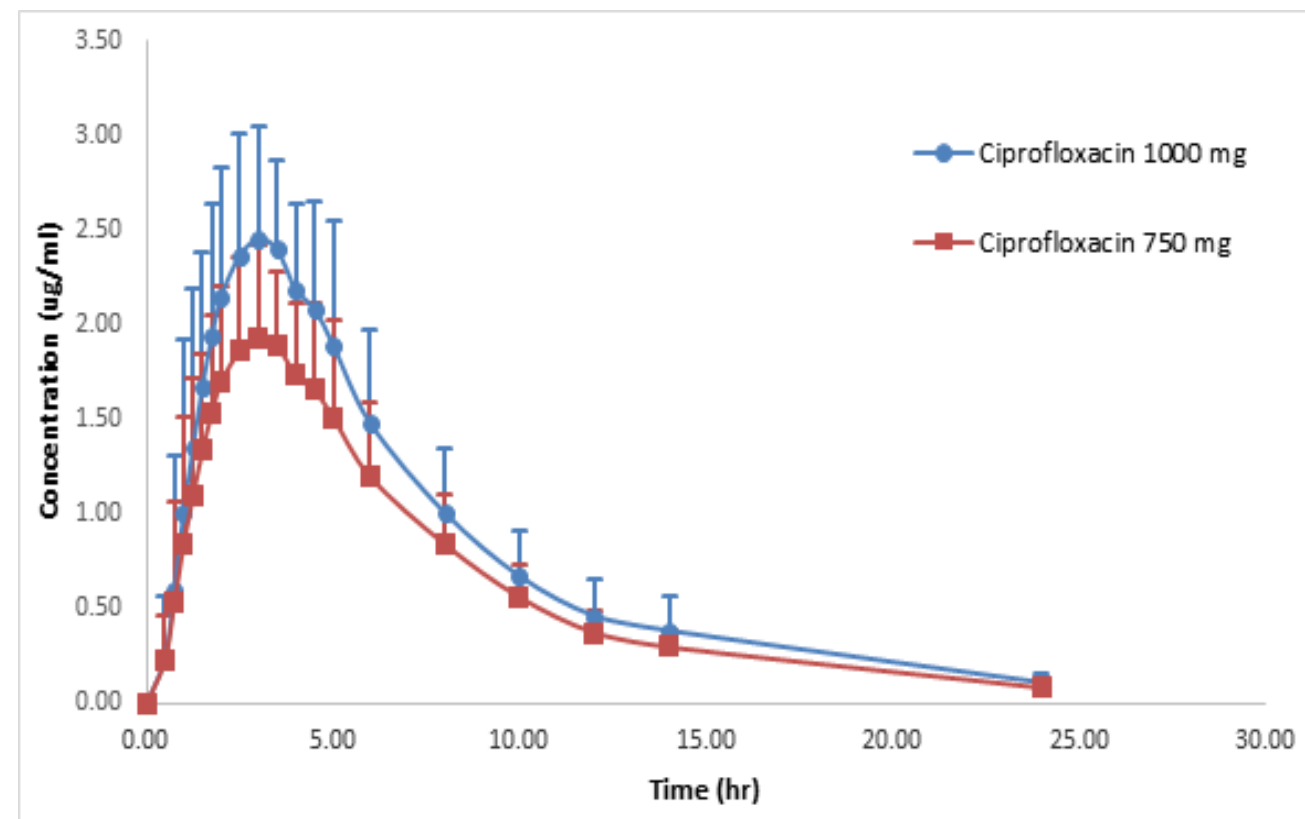

Figure 4: Plasma profile of ciprofloxacin at both doses of ciprofloxacin

\begin{tabular}{|l|l|l|l|l|l|}
\hline \multicolumn{1}{|c|}{ Pharmacokinetic Parameter } & \multicolumn{1}{|c|}{ Mean $\mathbf{1 0 0 0} \mathbf{~ m g}$} & \multicolumn{1}{|c|}{ STD } & Mean 750 $\mathbf{~ m g}$ & \multicolumn{1}{|c|}{ STD } & P-Value \\
\hline Cmax $(\mu \mathrm{g} / \mathrm{ml})$ & 2.45 & 0.53 & 1.93 & 0.43 & 0.000 \\
\hline Tmax $(\mathrm{hr})$ & 3.00 & 1.11 & 3.00 & 1.06 & 0.903 \\
\hline AUC $\left(\mu \mathrm{g}^{\star} \mathrm{hr} / \mathrm{ml}\right)$ & 19.12 & 4.64 & 15.30 & 3.30 & 0.001 \\
\hline Half life $(\mathrm{hr})$ & 5.26 & 0.87 & 4.98 & 0.32 & 0.221 \\
\hline Kel $(1 / \mathrm{hr})$ & 0.13 & 0.03 & 0.14 & 0.01 & 0.704 \\
\hline
\end{tabular}

Table 5: Pharmacokinetic parameters of ciprofloxacin at both doses $(1000,750) \mathrm{mg}$ 


\section{Conclusion}

In conclusion, major pharmacokinetic parameters, namely, Cmax, $\mathrm{AUC}_{0-24}$ of the two ciprofloxacin doses $1000 \mathrm{mg}$ and $750 \mathrm{mg}$ showed a clear relative trend in bioavailability and absorption in human plasma.

\section{Acknowledgement}

The authors wish to thank Jordan Center for Pharmaceutical Research and University of Petra for their endless help and support.

\section{References}

1. Gay JD, DeYoung DR, Roberts GD (1984) In vitro activities of norfloxacin and ciprofloxacin against Mycobacterium tuberculosis, M. avium complex, M. chelonei, M. fortuitum, and M. kansasii. Antimicrob Agents Chemother 26: 94-6.

2. Wingender W, Graefe K-H, Gau W, Förster D, Beermann D, et al. (1984) Pharmacokinetics of ciprofloxacin after oral and intravenous administration in healthy volunteers. Eur J Clin Microbiol 3: 355-9.

3. Chin NX, Neu HC (1984) Ciprofloxacin, a quinolone carboxylic acid compound active against aerobic and anaerobic bacteria. Antimicrob Agents Chemother 25: 319-26.

4. Carlucci G (1998) Analysis of fluoroquinolones in biological fluids by high-performance liquid chromatography. J Chromatogr A8 $12: 343-67$.

5. Campoli-Richards DM, Monk JP, Price A, Benfield P, Todd PA, et al. (1988) Ciprofloxacin. A review of its antibacterial activity, pharmacokinetic properties and therapeutic use. Drugs 35: 373-447.

6. Davis R, Markham A, Balfour JA (1996) Ciprofloxacin An updated review of its pharmacology, therapeutic efficacy and tolerability. Drugs51: 1019-74.

7. Fish DN (2001) Fluoroquinolone Adverse Effects and Drug Interactions. Pharmacotherapy 21: 253S-272S.

8. Fabre D, Bressolle F, Gomeni R, Arich C, Lemesle F, et al. (1991) Steady-state pharmacokinetics of ciprofloxacin in plasma from patients with nosocomial pneumonia: penetration of the bronchial mucosa. Antimicrob Agents Chemother 35: 2521-5.

9. Rohwedder RW, Bergan T, Thorsteinsson SB, Scholl H (1990) Transintestinal elimination of ciprofloxacin. Diagn Microbiol Infect Dis 13: 127-33.

10. Crump B, Wise R, Dent J (1983) Pharmacokinetics and tissue penetration of ciprofloxacin. Antimicrob Agents Chemother 24: 784-6.

11. Shaha A, Liua M-C, Vaughanb D, Heller AH (1999) Oral bioequivalence of three ciprofloxacin formulations following single-dose administration: 500 mg tablet compared with $500 \mathrm{mg} / 10 \mathrm{~mL}$ or $500 \mathrm{mg} / 5 \mathrm{~mL}$ suspension and the effect of food on the absorption of ciprofloxacin oral suspension. J Antimicrob Chemother 49-54. 12. Mallah E, Al Ani N, Abu DayyihW,Qinna N, Awad R, et al. (2014) Simultaneous Determination of Sildenafil and Glimepiride in Rat Plasma by Using LC-Ms Method and their Applications in Pharmacokinetic Interactions. J Clin Pharm 1: 1007-20.

13. Abu Dayyih W, Al-khader E, Mallah E, Arafat T (2013) Development and Validation of a Stability -Indicating HPLC Method for Determination of Bupivacaine in Human Plasma. Int J pharma Anal (IJPA) 38:1134-45.

14. Mallah E, Arafat B, Abu Awwad A, Abu Dayyih W, Mima M, et al. (2014) Comparative bioavailability of two different quetiapine doses (50 and $200 \mathrm{mg}$ )in healthy volunteers by using LC/MS method. J Chem Pharm Res 6: 559-69.

15. Valizadeh H, Hamishehkar H, Ghanbarzadeh S, Zabihian N, Zakeri-Milani P (2012) Pharmacokinetics and bioequivalence evaluation of two brands of ciprofloxacin $500 \mathrm{mg}$ tablets in Iranian healthy volunteers. Arzneimittelforschung 62: 566-70.

16. Abdallah RM, Alam SM, Awaad FM, Dham R, El-Kersh A, et al. (2002) Bioequivalence of Two Brands of Ciprofloxacin 750 Mg Tablets (Sarf and Ciprobay ${ }^{\circ}$ ) in Healthy Human Volunteers. Drug Dev Ind Pharm 28: 423-9.

17. M. Omari D,DaliaJohary, Isam I. Salem, NajiNajib, Assayed A.Sallam (2011) Bioequivalence of Two Oral Extended Release Formulations of Ciprofloxacin Tablets in Healthy Male Volunteers under Fed and Fasting Conditions. J Bioequiv Availab 3: 38-42.

18. Morera M, Cortes J, Ramos I, Moncada J, Fonseca L (2001) Bioequivalence of Two Oral Ciprofloxacin Formulations. Clin Drug Investig 21: 137-45.

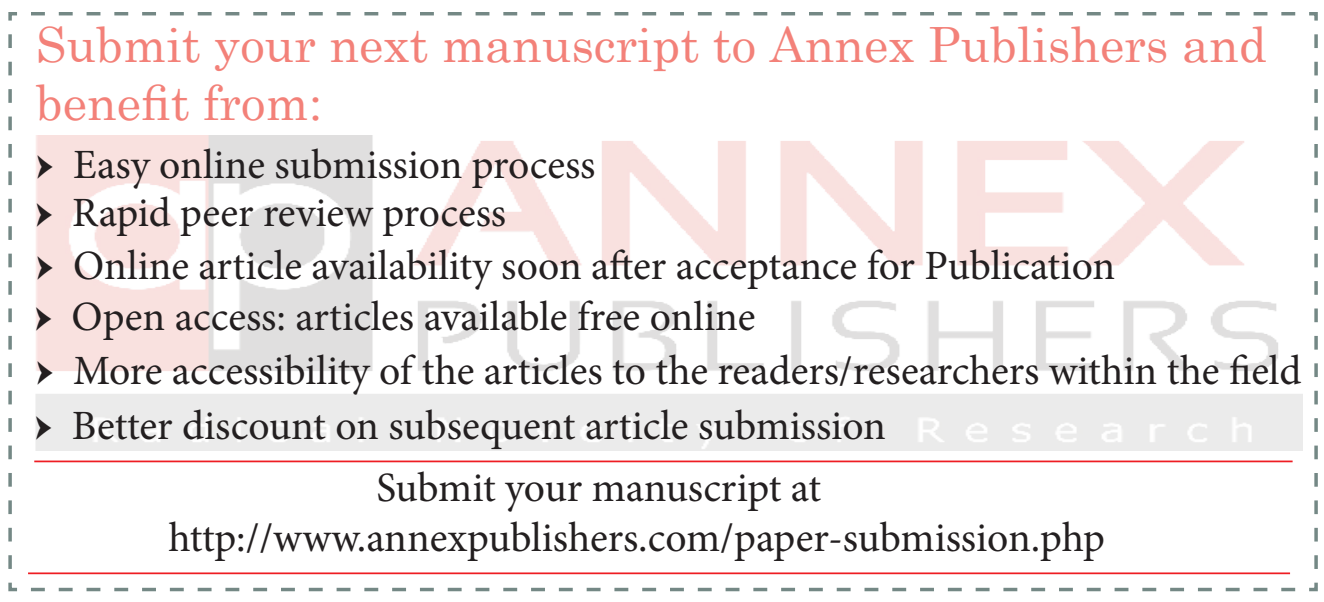

